\title{
Profiling the Determinants of Baby Weights in Bolgatanga Municipality of Ghana
}

\author{
Martin Amalitinga Akansuke \\ MSc. Applied Statistics-Department of Statistics, University for Development Studies \\ P. O. Box 24, Navrongo, Ghana
}

Tel: 233-200-929-195 E-mail: martinakansuke@yahoo.com

\begin{abstract}
Albert Luguterah
$\mathrm{PhD}$. Applied Statistics-Dean of Faculty of Mathematical Sciences

University for Development Studies. P. O. Box 24, Navrongo, Ghana

Tel: 233-205-191-000 E-mail: adlugu@yahoo.com
\end{abstract}

Sylvester Dodzi Nyadanu (Corresponding author)

MSc. Health Informatics-Department of Computer Science and College of Health Sciences

Kwame Nkrumah University of Science and Technology, Ghana

ECHO Research Group International. P. O. Box 424, Aflao, Ghana

Tel: 233-209-164-894 Email: echoresearchgroup.int@gmail.com

Derek Ngbandor Nawumbeni

MSc. Applied Statistics- Department of Statistics, University for Development Studies, Ghana

ECHO Research Group International, P. O. Box 424, Aflao, Ghana

Tel: 233-543-288-924 E-mail: nawumbenid@gmail.com

Timothy Adampah

MSc. Biometry-Department of Statistics, University for Development Studies, Ghana

ECHO Research Group International, P. O. Box 424, Aflao, Ghana

Tel: 233-205-235-351_E-mail: adampahtim@yahoo.com 


\section{Mll Macrothink}

Received: December 23, 2014

doi:10.5296/jbls.v6i2.7162
Journal of Biology and Life Science

ISSN 2157-6076

2015, Vol. 6, No. 2

Accepted: January 9, 2015 Published: February 26, 2015

URL: http://dx.doi.org/10.5296/jbls.v6i2.7162

\begin{abstract}
Introduction:

Birth weights and subsequent weights (weight-for-age of babies) have been found to play a vital role in early childhood development and have profound effect on later lives of children. The weight-for-age of babies, as a measure of child's growth, was found in several literatures as one of the key determinants of under-five mortality. This paper therefore deemed it crucial to explore how prognostic factors are influencing infants' growth in the weights of babies in Ghana using Bolgatanga municipality in the Upper East region of Ghana as case study.

Method:

The post-natal records of three hundred (300) nursing mothers were retrospectively followed from January to December 2013 in the seven health facilities of the municipality for the study. Inclusion criterion was used to recruit two hundred and thirty five (235) qualified subjects. The weight-for-age of babies and socio-demographics of the babies and the mothers were recorded. The determinants of infant growth in the weights of the babies were profiled.
\end{abstract}

Results:

The study disclosed that the mean birth weight in both sexes, $2.71 \mathrm{~kg}$ for males and $2.74 \mathrm{~kg}$ for females, were higher than the standard normal birth weights of $2.50 \mathrm{~kg}$ by WHO. The multivariate analysis of variance showed a nonlinear infants growth profile in the weights of babies during their first developmental year. The profile of the determinants showed that factors such as educational status and age of mother, breastfeeding type and sex of baby did not differ in the infants' weights by these groups even-though higher education and nonexclusive breastfeeding had positive effects. However, maternal factors such as: religious affiliations (socio-cultural practices), occupation, parity, injection as at last type of family planning practiced by nursing mothers were significant, highlighting the effect of these maternal socio-demographics and biological factors on infant growth and child survival.

\title{
Conclusion:
}

The profiles of the effects of the maternal determinants on the weights of babies considered in this study established that infant growth is non-linear. It could also be stated on the basis of the profile analysis that, the weights of babies in this municipality could be modeled for predictions using the maternal determinants such as occupation, parity group, injectable family planning method, breastfeeding type, educational level and socio-cultural practices (religion). The profile analysis of the effects of the maternal socio-demographics and biological factors on infant weights established that the infant's growth can be improved significantly by the nursing mothers, health service providers and the government if efforts are made to improve and/or modify the significant health indicators. 
Keywords: Birth and Baby weights, Profile analysis, Infant growth, Determinants

\section{Introduction}

Improving child health has been a key concern for many nations and this is evident from observations from numerous international summits and conferences including the Millennium Summit in 2000 (Luguterah and Nokoe, 2013). The health and survival of newborn children depend largely on how they are cared for. Even-though the care for infants is a very important component in the reduction of child mortality, it receives very low attention and seriousness. Recent worldwide evaluation points to the fact that commitment to raising the standards of the health status of newborn babies' yield meaningful socio-economic contributions. Further research on newborn babies revealed that child survival programme has assisted in the reduction of death rates among under-five year old babies over the past twenty five (25) years and the greatest impact has been on reducing mortality from diseases which attack infants and children over one month old. Hence, huge proportions of infant mortality take place between the first month of life (the neonatal period), a period when a child's risk of death is almost fifteen (15) times greater than at any other time before the first birthday (Yinger and Ransom, 2003). The incidence of infant mortality of which birth weight is a key health indicator, is a reflection of the socio-economic development of a country (Murthy, 1991) and hence its inclusion as the Millennium Development goals four (MDG4).

The World Health Organization define low birth weight as weight at birth less than $2.5 \mathrm{~kg}$. The global prevalence of low birth weight is $15.5 \%$, which means that about 20.6 million of such infants are born each year with $96.5 \%$ of them in developing countries. There is significant variation in low birth weight rates across the United Nations regions with the highest in south-central Asia (27.1\%) and the lowest in Europe (6.4\%). There are two types of low birth weight in infants, that is, small-for-date and pre-term babies. Small-for-date infants are those who are delivered after a full gestation period of 37-40 weeks but due to intrauterine growth retardation (IUGR), their birth weights are below $2.5 \mathrm{~kg}$. Furthermore, low birth weight can be caused by short gestation duration, (less than 37 weeks) as in the case of pre-term babies. Low birth weight is immensely connected with foetal and neonatal morbidity and mortality (McCormick, 1985; Gortmaker \& Wise, 1997; Caulfield et al 2004). These children are also prone to sudden infant death syndrome such as impaired neurologic and cognitive developments and the advent of chronic diseases later in life including diabetes and coronary heart disease, cardiovascular disease, high blood pressure, obstructive lung disease, high cholesterol concentrations and renal damage in adulthood (De Onis et al.1998; Bale et al. 2003).

The proportion of infants with low birth weight (LBW) reflects the socio-economic development of any region or country (Murthy, 1991). The incidence of LBW irrespective of gestational age is estimated to be 16 per 100 worldwide, 19 per 100 in the least developed and developing countries and 7 per 100 in the developed countries. The issue of LBW is 31 per 100 in south Asia followed by Middle East and North Africa with 15 per 100, Sub-Saharan Africa with 14 per 100, East Asia and Pacific 7 per 100. Asia accounted for 75 per 100, out of the total estimated IUGR infants with short gestation duration (less than $2.5 \mathrm{~kg}$ and greater than or equal 
to 37 weeks) and with $20 \%$ and 5\% born in Africa and Latin America, respectively. This is based on epidemiological observations that infants weighing less than $2.5 \mathrm{~kg}$ are approximately 20 times more likely to die than heavier infants (UNICEF-WHO, 2004). Low birth weight is mostly common in developing countries, where the burden of malnutrition and infectious diseases is heavy, and the incidence is estimated to be more than twice that of developed countries (Dryfuss et al., 2001). Being born with low birth weight is generally recognized as a disadvantage for the neonates and such babies are at higher risk of early growth retardation, infectious disease, development delay and death during infancy and childhood. In sub-Saharan Africa, estimated rate of low birth weight is $14 \%$ live birth based on statistics derived from health facilities, which constitute about $35 \%$ of all live births occurring in the region (UNICEF-WHO, 2004).

Since the adoption of the MDG4, child mortality has received a lot of attention leading to a significant decline in its incidence but these declines are found to be inadequately significant to achieve the set MDG4 (UN, 2009; IGME, 2010; IGME, 2011 and Hagen, 2007 In Luguterah and Nokoe, 2013). Because LBW as a key health indicator of child health remains a burden on healthcare practitioners, government and stakeholders, a profile analysis of child growth using longitudinal study is indispensable as a foundation for unveiling the infant growth pattern and its correlating determinants. Hence this research is aimed at examining the effects of some prognostic factors influencing infant growth by closely monitoring weight-for-age of babies in the Bolgatanga Municipality of Ghana during the infant developmental period.

\section{Research Method}

\subsection{Data Used}

A historical data for this study was obtained from the seven health facilities in the Bolgatanga Municipality, namely, Bolgatanga referral hospital, Coronation Clinic (Plaza), Amiah Hospital, Afrikids Medical Centre, Bolgatanga Health Centre (Aningazanga Health Centre), Zuarungu Health Centre and Asankunde Memorial Clinic. The registers and the post natal cards of women who delivered from January 2013 to December 2013 were critically reviewed. The dataset collected includes: maternal age, marital status, and breast feeding type, family planning type, religious affiliation, educational status, parity and occupation.

\subsection{Profile Analysis Approach}

This paper used longitudinal study in which there is a small number of time points at which the individuals give responses, but in this case there is a large amount of data measured at any given time point. The pattern of mean change in baby weight is portrayed through the profile analysis. The profile plot to observe the trajectory of change in baby weight over time was carried out. The following covariates; sex of the baby, marital status, breast feeding, maternal educational level, family planning type employed by the mother, and mother's religious affiliation were used to construct the profile plots. We constructed profiles for the means of baby weight $\left(\bar{x}_{0}, \bar{x}_{1}, \bar{x}_{2}, \ldots, \bar{x}_{6}\right)$ against the time points $t=0,1,2, \ldots ., 12$ for the various groups. Then a scatter plot for the means of average change in weights of babies over time was 


\section{Macrothink}

Journal of Biology and Life Science ISSN 2157-6076 2015, Vol. 6, No. 2

performed and the pattern fitted. The Akaike's information criterion (AIC) and Bayesian Information Criterion (BIC) were used to select the best growth model to fit the prediction of the trend model.

\subsubsection{Shapiro-Wilks Test for Normality}

Given a set of observations $\bar{x}_{1}, \bar{x}_{2}, \bar{x}_{3}, \ldots, \bar{x}_{n}$ sorted in either descending or ascending order, the test statistics of Shapiro and Wilks, $W$ is defined as:

$$
W=\frac{\left(\sum_{i=1}^{n} a_{i} x_{i}\right)^{2}}{\sum_{i=1}^{n}\left(x_{i}-\bar{x}\right)^{2}}
$$

where $\bar{x}=1 / n \sum_{i=1}^{n} x_{i}$, is the samples mean and $a_{i}$ for $i=1,2,3, \ldots, n$ are a set of "weight" whose values depend only on the sample size $n$. (Spiro and Wilks, 1980)

\subsubsection{ARCH-LM Test for Conditional heteroscedasticity}

This occurs when the variance of the residuals is not constant. To ensure that the fitted model is adequate, the assumption of constant variance must be achieved. The ARCH-LM test was used to test for the presence of conditional heteroscedasticity in the model residuals. The test hypothesis is as follows;

$H_{0}$ : There is no heteroscedasticity in the model residuals

$H_{1}$ : There is heteroscedasticity in the model residuals

The test statistic is

$$
\mathrm{LM}=n R^{2}
$$

where $n$ is the number of observations and $R^{2}$ is the coefficient of determination of the auxiliary residual regression given as

$$
e_{t}^{2}=\beta_{0}+\beta_{1} e_{t-1}^{2}+\beta_{2} e_{t-2}^{2}+\ldots+\beta_{q} e_{t-q}^{2}+v_{t}
$$

where $e_{t}$ is the residual, $\beta_{0}$ is a random-effect intercept, the index $t$ is the time, $\beta_{1} \ldots . . \beta q$ are fixed-effect parameters associated with the non-random predictors and error factor $v_{t}$

The null hypothesis is rejected when the $p$-value is less than the level of significance and is concluded that there is heteroscedasticity Engle (1982). 


\section{Macrothink}

\subsection{The Profile Trend}

Multivariate Analysis of variance (MANOVA) was performed to fit the profile trend and to complement and confirm the profile plot of test of parallelism. Assuming parallelism, the infant growth in baby weights were fully tested for the parallelism, equality and flatness.

\section{Results}

\subsection{Socio-demographic characteristics of Mothers and Babies}

The study reveals that mothers who belonged to the age group of 25-32years were 132 , representing approximately 56\%, those between 17-24years were 66 with a percentage of approximately $28 \%$ whilst maternal age group 33years and above were 37 corresponding to an estimated percentage of 16 . On educational category, mothers who attained Junior High School emerged the highest with a value of 66 yielding an estimated percentage of 28, those who completed Senior High School as well as parents who got tertiary education recorded the same figure of 51 indicating an estimated percentage of 22 each. Forty of the mothers completed primary school representing an approximate percentage of 17 whilst 27 mothers did not receive any formal level of education with an estimated percentage of 11 . Mothers who practiced exclusive breast feeding were 138 giving an estimated percentage of 59 compared to 49 and 48 mothers who did nonexclusive breast feeding and mixed (breast milk and water only) respectively. Mothers who had given birth the first time were 119 relative to 98 and 18 mothers who delivered between 2-3 and 4-5 births respectively. Out of a total of 235 mothers, 136 of them were self-employed with an estimated percentage of 57.87 , mothers who were government employees had approximately 21.70 percent, and those who were not employed indicated an approximated percentage of 14 whilst 15 parents were students indicating an estimated percentage of 6 . One hundred and thirty (130) of the babies whose weights were measured were males whilst 105 were females. A total of 173 mothers were Christians representing approximately 74 percent whilst 36 were Muslim and 26 practiced traditional religion (Table 1).

Table 1. Distribution of characteristic of mother and gender of baby

\begin{tabular}{|l|l|l|}
\hline Variable & Freq. & Percent \\
\hline Mother's age group \\
\hline $17-24$ & 66 & 28.090 \\
\hline $25-32$ & 132 & 56.170 \\
\hline $33+$ & 37 & 15.740 \\
\hline Breastfeeding & \multicolumn{3}{|l|}{} \\
\hline Exclusive & 138 & 58.720 \\
\hline Mixed & 48 & 20.430 \\
\hline Nonexclusive & 49 & 20.850 \\
\hline Occupation & \multicolumn{3}{|l|}{} \\
\hline Unemployed & 33 & 14.040 \\
\hline Student & 15 & 6.380 \\
\hline Self employed & 136 & 57.870 \\
\hline Government & 51 & 21.700 \\
\hline
\end{tabular}




\begin{tabular}{|l|l|l|}
\hline Gender & & \\
\hline Male & 130 & 55.320 \\
\hline Female & 105 & 44.680 \\
\hline Variable & Freq. & Percent \\
\hline Education & & \\
\hline None & 27 & 11.490 \\
\hline Primary & 40 & 17.020 \\
\hline JHS & 66 & 28.090 \\
\hline SHS & 51 & 21.700 \\
\hline Tertiary & 51 & 21.700 \\
\hline Parity group & & \\
\hline 1 & 119 & 50.640 \\
\hline $2-3$ & 98 & 41.700 \\
\hline $4-5$ & 18 & 7.660 \\
\hline Marital status & & \\
\hline Single & 34 & 14.470 \\
\hline Married & 201 & 85.530 \\
\hline Religion of mother & & \\
\hline Christianity & 173 & 73.620 \\
\hline Islamic & 36 & 15.320 \\
\hline Traditional & 26 & 11.060 \\
\hline
\end{tabular}

Table 2 represents the descriptive statistics of mean weights of babies in the study showing a general increase in weight over the study period. The mean weight of babies at birth was $2.72 \mathrm{~kg}$ with standard deviation of $0.46 \mathrm{~kg}$. The minimum and maximum weights at birth were $1.20 \mathrm{~kg}$ to $4.20 \mathrm{~kg}$ respectively. That of the average weight of a twelve month (i.e. one year) old baby was $9.61 \mathrm{~kg}$ with standard deviation of approximately $1.12 \mathrm{~kg}$. The minimum and maximum weight values at one year of age was $6.40 \mathrm{~kg}$ and $13.30 \mathrm{~kg}$ respectively. It is observed that the mean change in weights of the babies at a one year period did not follow increasing pattern overtime and that the weight of a baby does not necessarily depend on when the individual was born.

Table 2. Summary statistics of baby weights over time (in months)

\begin{tabular}{|l|l|l|l|l|}
\hline Time(month) & Mean & Sd & Min & Max \\
\hline 0 & 2.723 & 0.460 & 1.200 & 4.200 \\
\hline 1 & 4.161 & 0.978 & 1.200 & 7.000 \\
\hline 2 & 4.949 & 1.073 & 1.500 & 8.000 \\
\hline 3 & 5.730 & 1.067 & 2.300 & 9.000 \\
\hline 4 & 6.342 & 1.123 & 2.400 & 9.500 \\
\hline 5 & 6.849 & 1.099 & 3.000 & 10.000 \\
\hline 6 & 7.135 & 1.194 & 3.000 & 12.000 \\
\hline 7 & 7.432 & 1.147 & 3.400 & 12.600 \\
\hline 8 & 7.732 & 1.184 & 4.500 & 11.500 \\
\hline 9 & 8.018 & 1.158 & 5.500 & 14.000 \\
\hline 10 & 8.422 & 1.230 & 5.800 & 14.000 \\
\hline
\end{tabular}




\begin{tabular}{|l|l|l|l|l|}
\hline 11 & 8.760 & 1.242 & 6.200 & 13.000 \\
\hline 12 & 9.605 & 1.116 & 6.400 & 13.300 \\
\hline Total & 6.758 & 2.170 & 1.200 & 14.000 \\
\hline
\end{tabular}

The baby weights overtime stratified by gender is presented in Table 3. Male babies had the lower mean birth weight of $2.71 \mathrm{~kg}$ than $2.74 \mathrm{~kg}$ of the females. The standard deviations of the male and female babies at birth were $0.45 \mathrm{~kg}$ and $0.48 \mathrm{~kg}$ respectively. The minimum weights at birth of males and females were $1.30 \mathrm{~kg}$ and $1.20 \mathrm{~kg}$ respectively with respective maximum weights of $4.20 \mathrm{~kg}$ and $4.10 \mathrm{~kg}$. Thus although the mean showed that female babies were heavier at birth, they gave the least minimum and maximum weights at birth with a greater standard deviation compared to that of the males. The mean weights of one year old babies (average weight at the $12^{\text {th }}$ month) showed that males were greater with $9.61 \mathrm{~kg}$ weight than that their female counterparts who weighed $9.60 \mathrm{~kg}$ and with a standard deviation of $0.98 \mathrm{~kg}$, less than that $1.27 \mathrm{~kg}$ of baby girls. Males had minimum weight at month twelve of $6.90 \mathrm{~kg}$ is greater than that for females of $6.40 \mathrm{~kg}$. The mean one year maximum weight for males of $11.60 \mathrm{~kg}$ was less than that for females $(13.30 \mathrm{~kg})$. The mean weights of females at birth (i.e. month zero) are higher compared to the mean weights of boys at birth but lower at the twelve month for females compared to that for males at the same period. Both sexes at birth, however, recorded higher mean weights compared to the World Health Organization standard for normal weight of a baby at birth (i.e. $2.50 \mathrm{~kg}$ ).

Table 3. Summary statistics of baby weights over time (in months) by sex

\begin{tabular}{|l|l|l|l|l|l|l|l|l|}
\hline \multirow{2}{*}{ Month } & \multicolumn{2}{|l|}{ Mean } & \multicolumn{2}{c|}{ Sd } & \multicolumn{2}{c|}{ Minimum } & \multicolumn{2}{c|}{ Maximum } \\
\cline { 2 - 9 } & Male & Female & Male & Female & Male & Female & male & Female \\
\hline 0 & 2.71 & 2.74 & 0.45 & 0.48 & 1.30 & 1.20 & 4.20 & 4.10 \\
\hline 1 & 4.18 & 4.13 & 0.98 & 0.98 & 1.80 & 1.20 & 6.60 & 7.00 \\
\hline 2 & 4.91 & 4.99 & 1.10 & 1.04 & 1.90 & 1.50 & 8.00 & 7.10 \\
\hline 3 & 5.73 & 5.73 & 1.08 & 1.06 & 2.30 & 3.10 & 9.00 & 8.20 \\
\hline 4 & 6.29 & 6.40 & 1.16 & 1.07 & 2.40 & 3.10 & 9.50 & 9.00 \\
\hline 5 & 6.78 & 6.93 & 1.13 & 1.06 & 3.00 & 4.00 & 10.00 & 10.00 \\
\hline 6 & 7.17 & 7.09 & 1.15 & 1.25 & 3.00 & 3.50 & 11.50 & 12.00 \\
\hline 7 & 7.41 & 7.46 & 1.10 & 1.21 & 4.20 & 3.40 & 12.60 & 11.00 \\
\hline 8 & 7.74 & 7.72 & 1.20 & 1.17 & 4.60 & 4.50 & 11.00 & 11.50 \\
\hline 9 & 8.01 & 8.03 & 1.08 & 1.26 & 5.50 & 5.80 & 11.20 & 14.00 \\
\hline 10 & 8.37 & 8.49 & 1.16 & 1.31 & 6.00 & 5.80 & 12.00 & 14.00 \\
\hline 11 & 8.68 & 8.85 & 1.11 & 1.39 & 6.50 & 6.20 & 12.00 & 13.00 \\
\hline 12 & 9.61 & 9.60 & 0.98 & 1.27 & 6.90 & 6.40 & 11.60 & 13.30 \\
\hline
\end{tabular}

\subsection{Profile Analysis}

\subsubsection{Profile Plot of Mean Baby Weights by Breastfeeding Type}

The profiles plot in figure 1 shows that the mean change in weights of babies over the period of observation for breast feeding type, varied over time with nearly the same pattern. This implies that the average change in weights of babies within breast feeding type may be parallel or similar. 


\section{Macrothink}

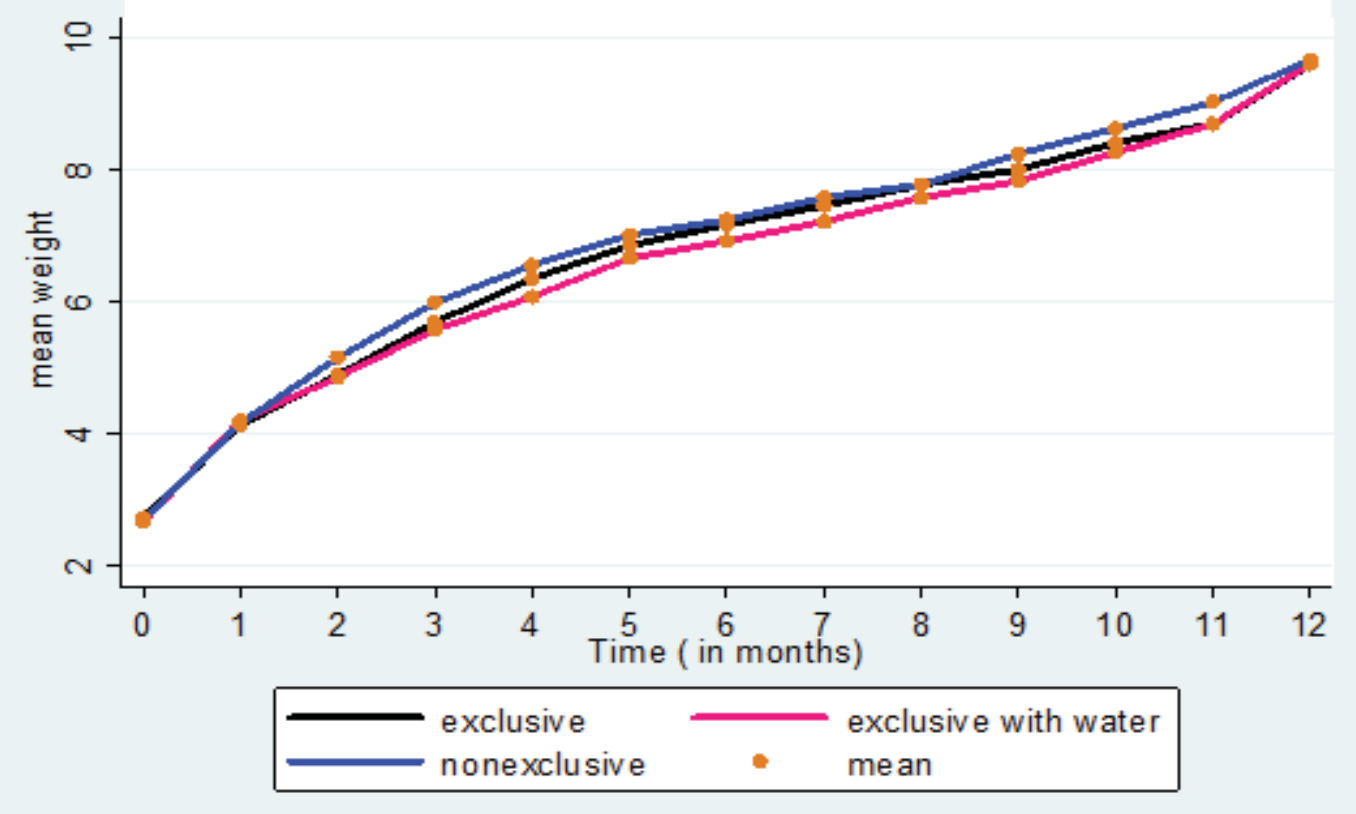

Figure 1. Profile plot of mean baby weights by breastfeeding type

\subsubsection{Profile Plot of Mean Baby Weights by Mother'S Education}

Figure 2 of the profiles plot shows that the average changes in weights of babies among the different levels of maternal education were changing over time and the pattern was about the same. This suggests that the mean change in weights of babies may be similar irrespective of the educational levels of mothers.

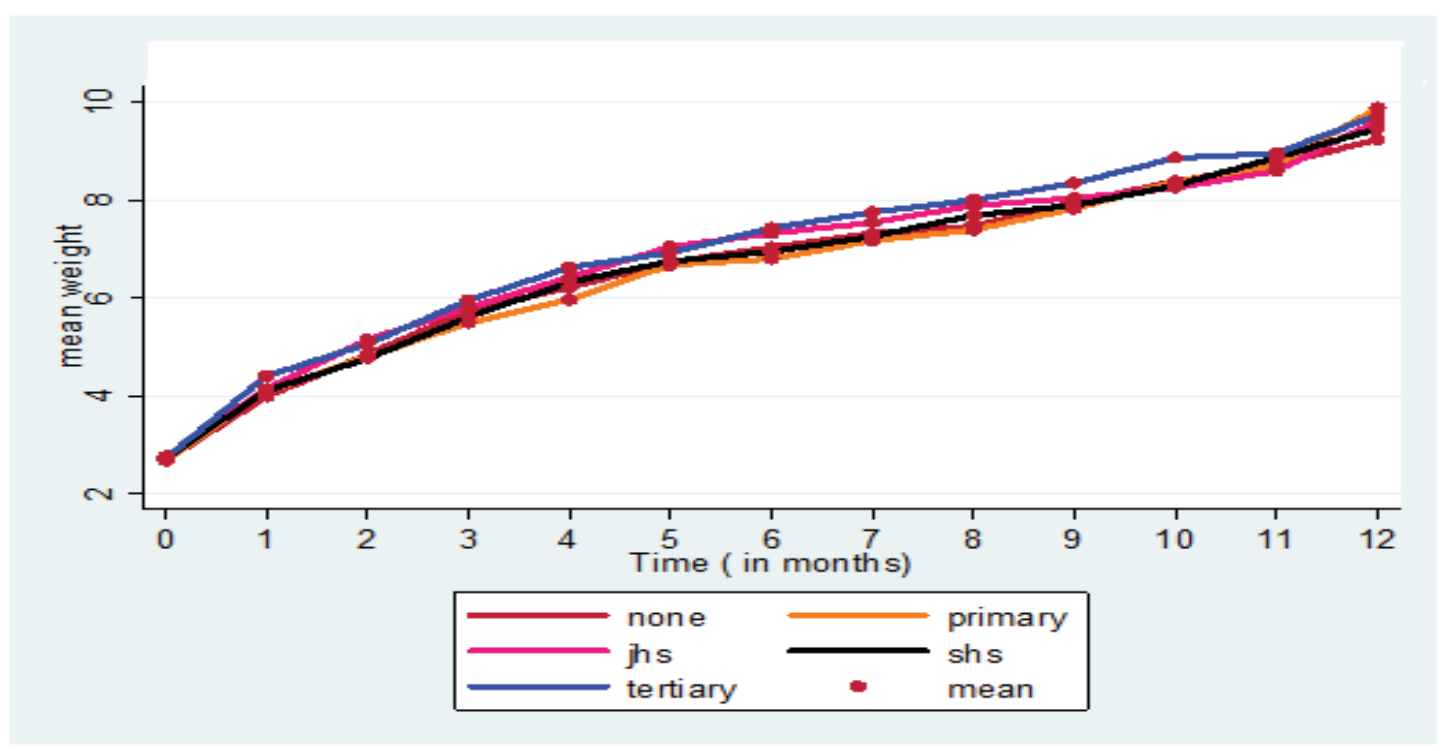

Figure 2. Profile plot of mean baby weights by mother's education 


\section{Macrothink}

\subsubsection{Profile Plot of Mean Baby Weights by Religion}

The profile (Figure 3) of the mean change in weights of babies against time in respect of their maternal religious affiliation depicts similar pattern. It gives the impression that the average change in weights of babies across maternal religious denomination could be similar or parallel.

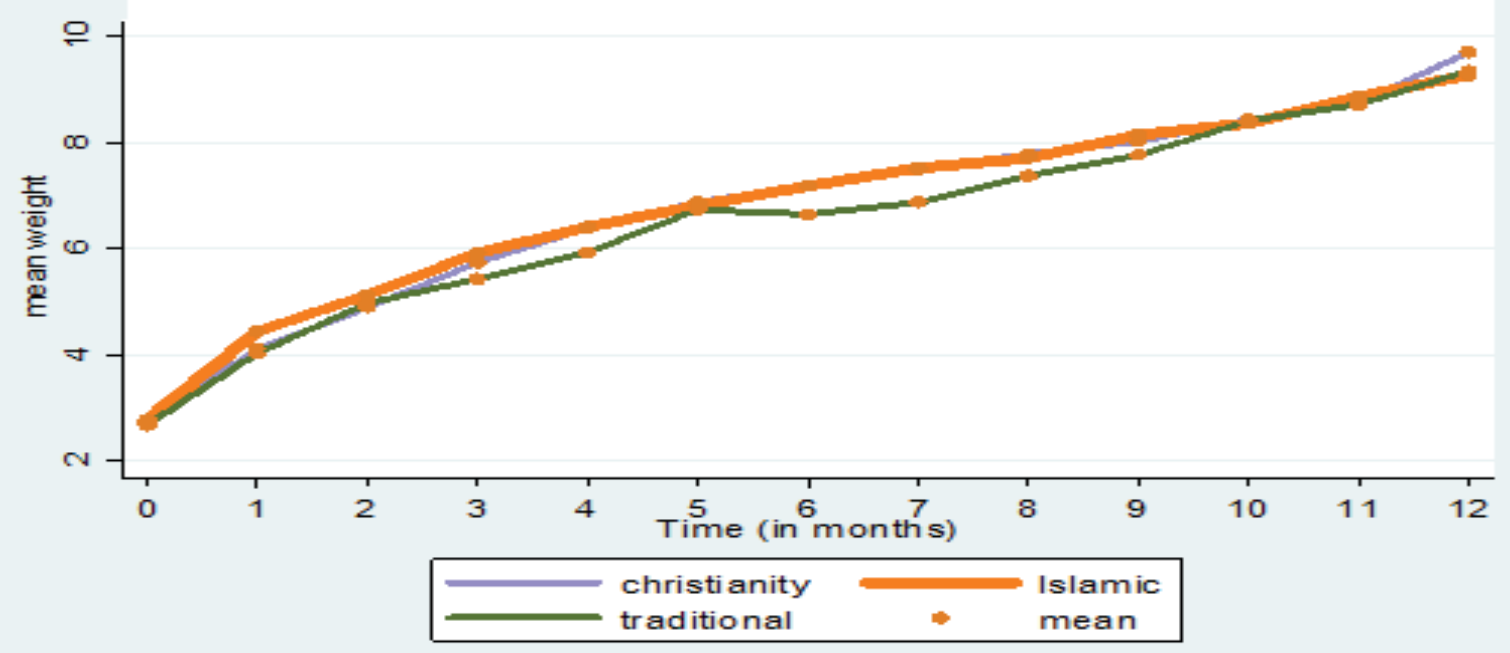

Figure 3. Profile plot of mean baby weights by religion

\subsubsection{Profile Plot of Mean Baby Weight by Contraceptive Use}

Apart from the norplant showing a drop in weight of babies in their $9^{\text {th }}$ to $10^{\text {th }}$ month and a sharp rise in weight from the $10^{\text {th }}$ to the $11^{\text {th }}$ month and a subsequent drop afterward, the mean change in weights of babies was almost the same over the period of observation but injectable leads in most instances. This suggests that apart from norplant, the other contraceptives used by mothers may be similar (Figure 4). 


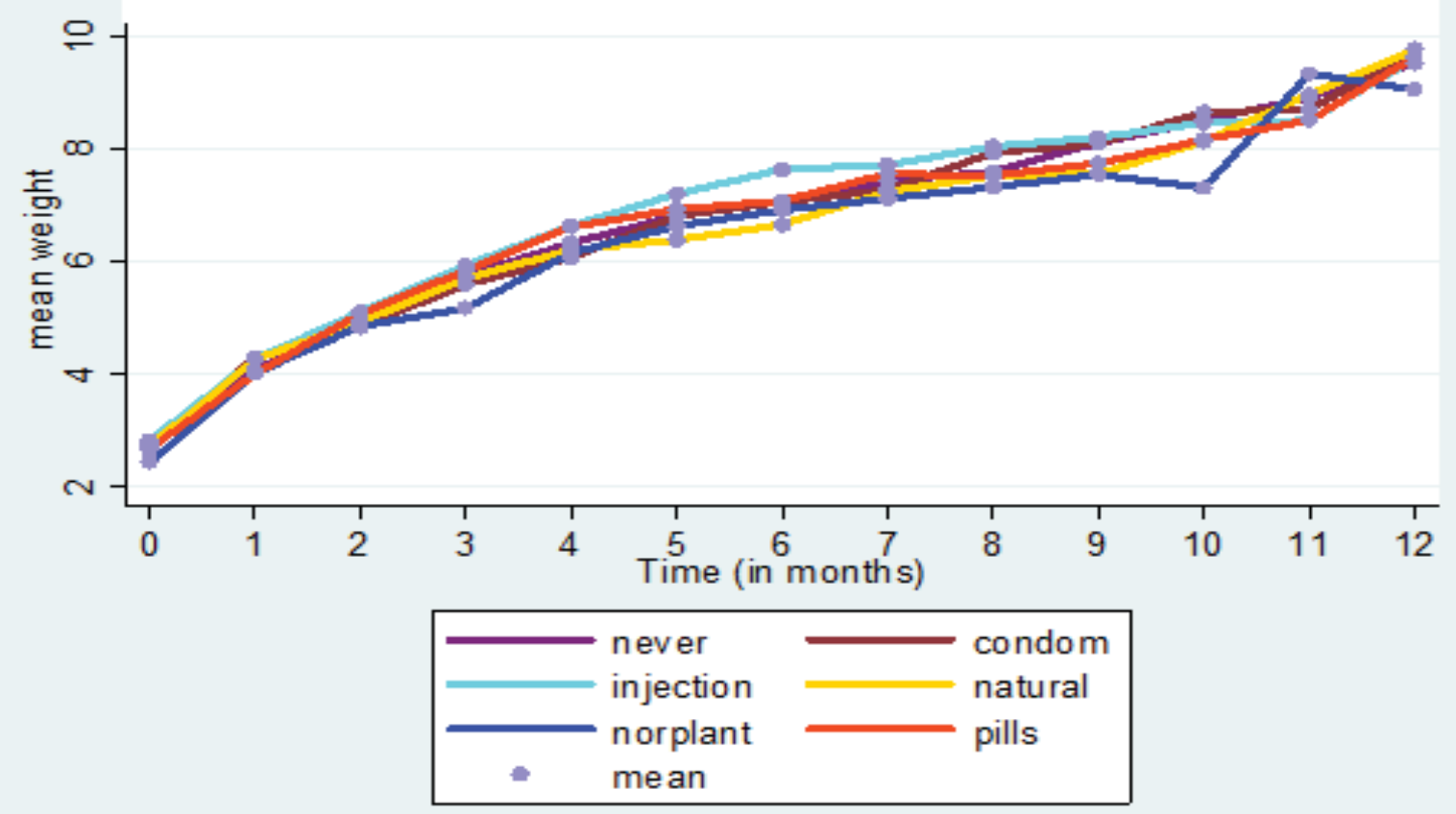

Figure 4. Profile plot of mean baby weight by contraceptive used

\subsubsection{Profile Plot of Mean Baby Weight by Mother'S Age Group}

The profile plot as indicated in Figure 5 shows that the mean change in weights of babies for mother's age group had changed over time and follows the same pattern with $17-24$ years age group leading slightly. This implies that the mean change in weights of babies across the mother's age groups was similar or parallel.

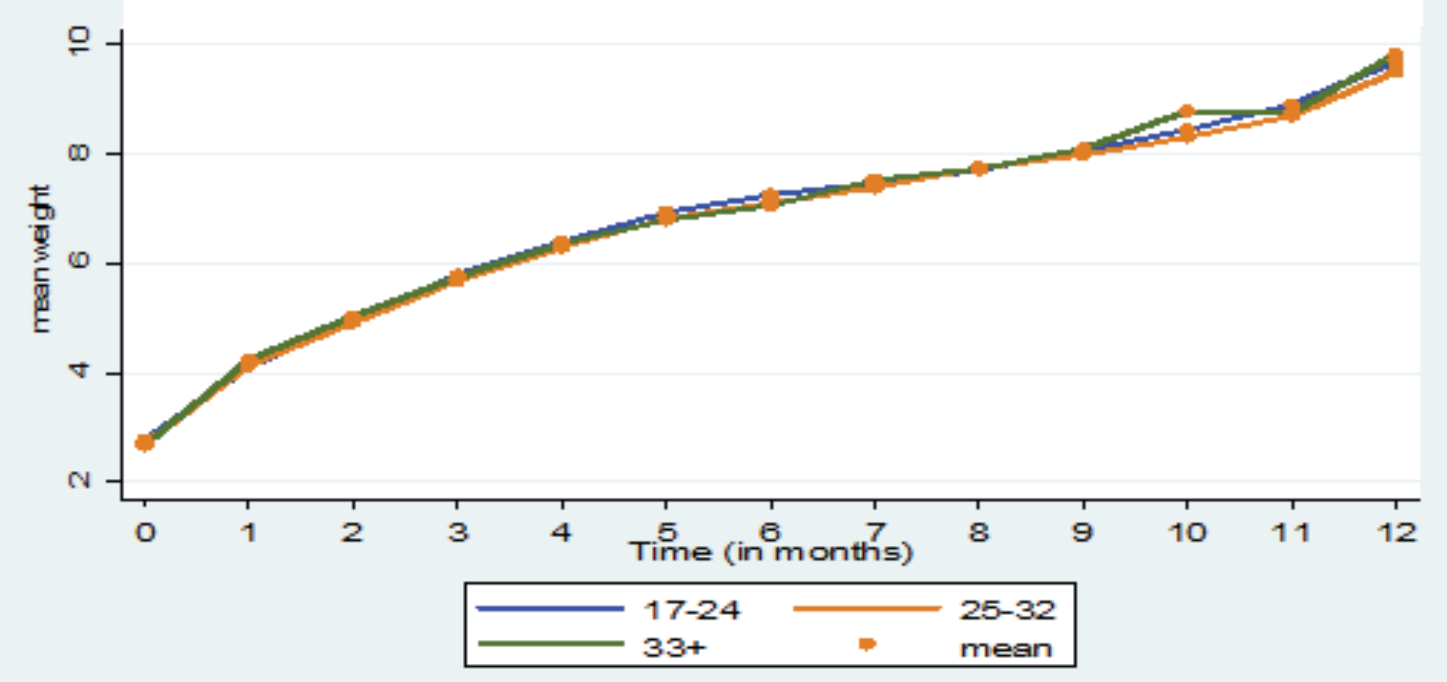

Figure 5. Profile plot of mean baby weight by mother's age group 


\section{Macrothink}

\subsubsection{Profile Plot of Mean Baby Weight by Mother's Occupation}

This profile plot, figure 6 , indicates that the mean change in weights of babies within the twelve months according to their mother's occupation status follows the same infant growth pattern.

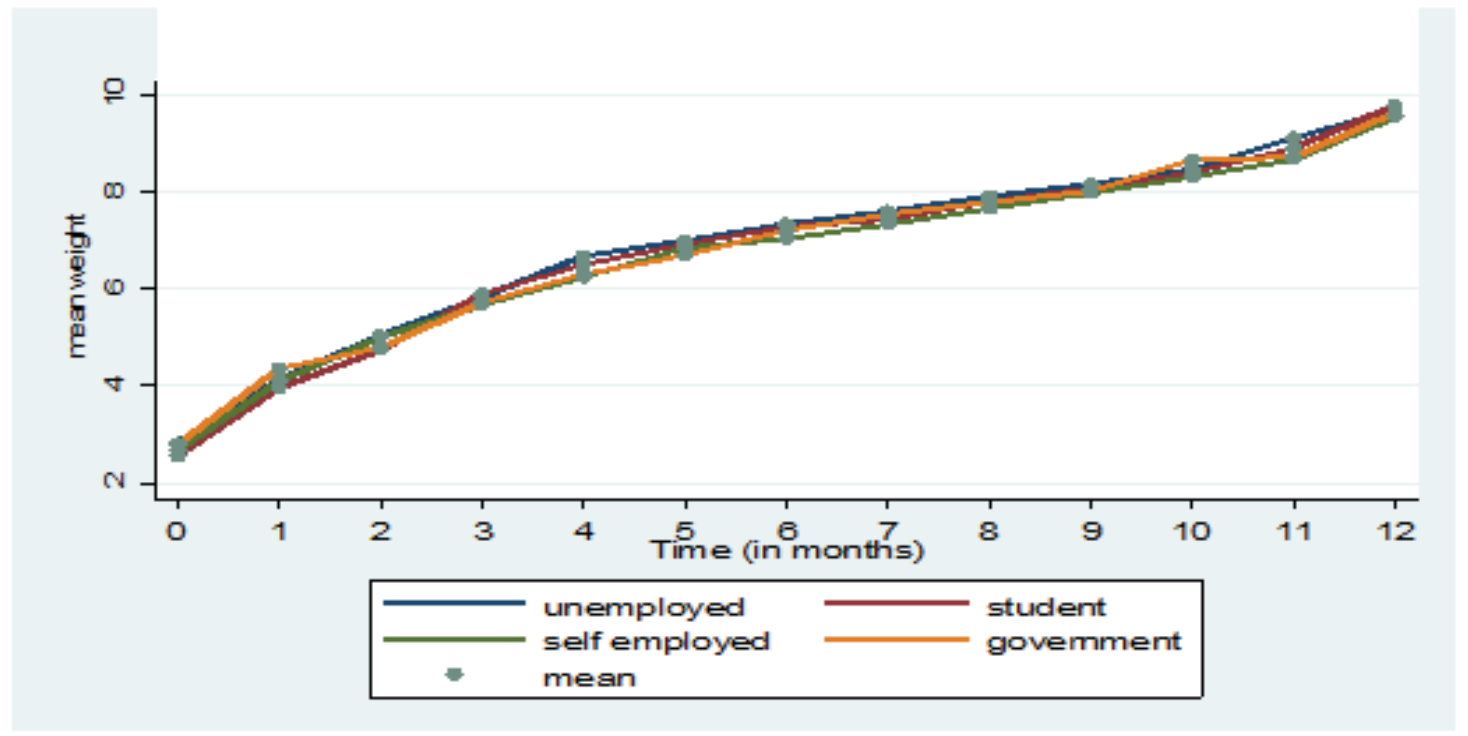

Figure 6. Profile plot of mean baby weight by mother's occupation

\subsubsection{Profile Plot of Mean Baby Weight by Parity Group}

The profiles indicate that the average change in weights of babies for each parity group increased over time in a similar pattern. However, mothers who gave birth four to five times were lagging. This gives the suggests that the average change in weights of babies within parity group might be similar or parallel for mothers who delivered once to three times (Figure 7). 


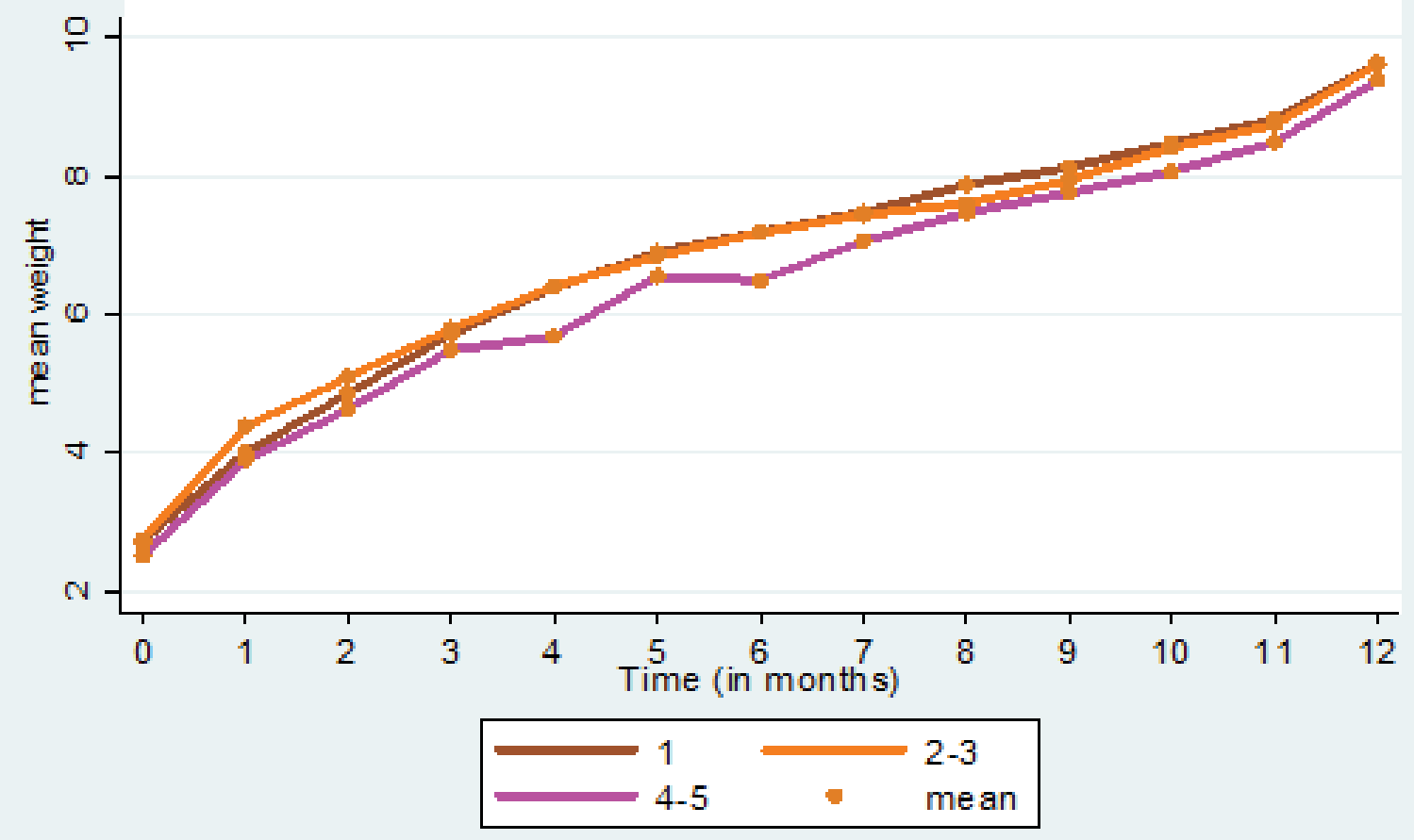

Figure 7. Profile plot of mean baby weight by parity group

\subsubsection{Profile Plot of Mean Baby Weight by Gender}

Figure 8 showed that the mean change in weights of babies for both male and female over time did not have variations in their patterns. This means that the mean change in weight of babies with respect to gender may be similar.

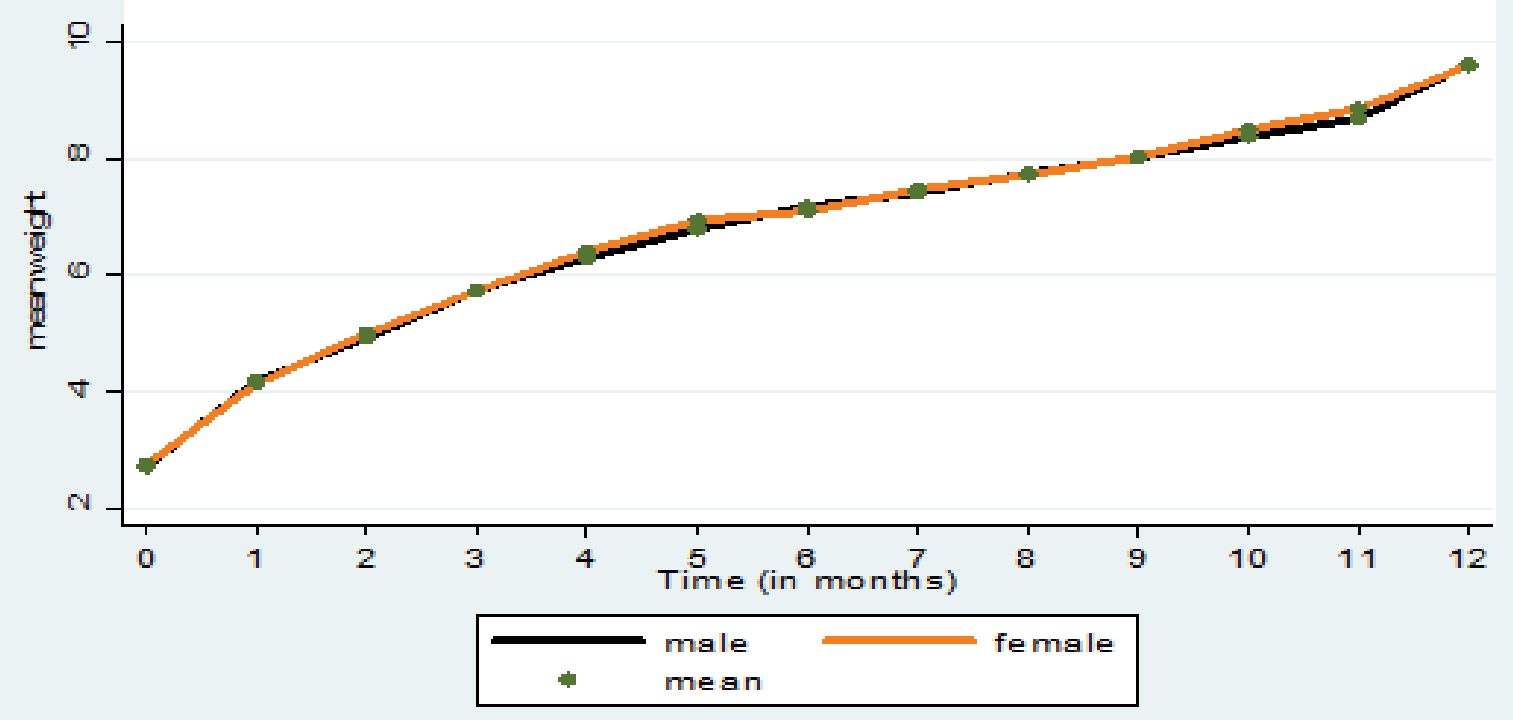

Figure 8 . Profile plot of mean baby weights by gender 


\section{1ll Macrothink}

\subsubsection{MANOVA Test for Groups}

The results of the multivariate analyses of variance test for the mean weights of babies for the groups are shown in Table 4. The tests suggested that the profiles for the different levels which are: maternal educational status, the last type of family planning method the mother stopped using before pregnancy, marital status, maternal occupational status and maternal religious affiliation significantly differed at the $5 \%$ significance level and therefore their profiles could be said to be parallel.

Table 4. Multivariate Analysis of Variance Test for Groups

\begin{tabular}{|c|c|c|c|}
\hline Variable & Value & F Value & $\operatorname{Pr}>F$ \\
\hline \multicolumn{4}{|l|}{ Sex of baby } \\
\hline Wilks' Lambda & 0.9237 & 1.2800 & 0.2295 \\
\hline Pillai' Trace & 0.0763 & 1.2800 & 0.2295 \\
\hline Hotelling-Lawey & 0.0826 & 1.2800 & 0.2295 \\
\hline TraceRoy's Greatest Root & 0.0826 & 1.2800 & 0.2295 \\
\hline \multicolumn{4}{|l|}{ Religion } \\
\hline Wilks' Lambda & 0.8152 & 1.6600 & 0.0230 \\
\hline Pillai’ Trace & 0.1939 & 1.6700 & 0.0223 \\
\hline Hotelling-Lawey & 0.2154 & 1.6600 & 0.0238 \\
\hline TraceRoy's Greatest Root & 01276 & 1.98 & 0.0238 \\
\hline \multicolumn{4}{|l|}{ Education } \\
\hline Wilks' Lambda & 0.5061 & 2.8900 & 0.0000 \\
\hline Pillai' Trace & 0.5741 & 2.6300 & 0.0000 \\
\hline Hotelling-Lawey & 0.8265 & 3.1700 & 0.0000 \\
\hline TraceRoy's Greatest Root & 0.6201 & 9.7300 & 0.0000 \\
\hline \multicolumn{4}{|l|}{ Age } \\
\hline Wilks' Lambda & 0.8756 & 1.0600 & 0.3843 \\
\hline Pillai' Trace & 0.1274 & 1.0600 & 0.3902 \\
\hline Hotelling-Lawey & 0.1386 & 1.0700 & 0.3787 \\
\hline TraceRoy's Greatest Root & 0.1062 & 1.6500 & 0.0744 \\
\hline \multicolumn{4}{|l|}{ Parity group } \\
\hline Wilks' Lambda & 0.8483 & 1.3300 & 0.1341 \\
\hline Pillai' Trace & 0.1574 & 1.3300 & 0.1327 \\
\hline Hotelling-Lawey Trace & 0.1729 & 1.3200 & 0.1356 \\
\hline Roy's Greatest Root & 0.1106 & 1.7200 & 0.0592 \\
\hline
\end{tabular}




\begin{tabular}{|l|l|l|l|}
\hline Marital Status & \multicolumn{3}{|l|}{} \\
\hline Wilks' Lambda & 0.7644 & 4.7700 & 0.0000 \\
\hline Pillai' Trace & 0.2356 & 4.7700 & 0.0000 \\
\hline Hotelling-Lawey & 0.3082 & 4.7700 & 0.0000 \\
\hline Trace Roy's Greatest Root & 0.3082 & 4.7700 & 0.0000 \\
\hline Breast Feeding & \multicolumn{3}{|l|}{} \\
\hline Wilks' Lambda & 0.8791 & 1.0300 & 0.4265 \\
\hline Pillai' Trace & 0.1228 & 1.0200 & 0.4437 \\
\hline Hotelling-Lawey & 0.1355 & 1.8200 & 0.0416 \\
\hline Trace Roy's Greatest Root & 0.1173 & 1.8200 & 0.0416 \\
\hline Family Planning & \multicolumn{3}{|l}{} \\
\hline Wilks' Lambda & 0.5649 & 1.8900 & 0.0001 \\
\hline Pillai' Trace & 0.5273 & 1.8600 & 0.0001 \\
\hline Hotelling-Lawey & 0.6210 & 1.9100 & 0.0000 \\
\hline Trace Roy's Greatest Root & 0.2715 & 4.2800 & 0.0000 \\
\hline & \multicolumn{3}{|l}{} \\
\hline Occupation & 0.6835 & 2.1000 & 0.0002 \\
\hline Wilks' Lambda & 0.3450 & 2.0300 & 0.0003 \\
\hline Pillai's Trace & 0.4219 & 2.1600 & 0.0001 \\
\hline Hotelling-Lawey & 0.2929 & 4.5700 & 0.0000 \\
\hline Trace Roy's Greatest Root & \multicolumn{3}{|l|}{} \\
\hline
\end{tabular}

\subsubsection{Multivariate Test of Parallelism, Equality and Flatness by Sex of Baby}

Each of the four multivariate tests for parallelism and equality by gender of babies from table 5 gave a $p$-value of greater than 0.05 . We therefore fail to reject the hypothesis of same profiles and conclude that the pattern of change in weights of babies did not differ by gender in both cases. Hence, the test of flatness was performed. The results of the test of flatness showed that all the four multivariate tests gave $\mathrm{p}$-values less than 0.05 . We therefore reject the hypothesis of same profiles and conclude that the pattern of change in mean weights of babies differed by gender overtime.

Table 5. Multivariate test of parallelism, equality and flatness by sex of baby

\begin{tabular}{|c|c|c|c|c|}
\hline Source & & Statistic & F Value & Prob $>F$ \\
\hline \multicolumn{5}{|c|}{ Test of Parallelism } \\
\hline \multirow[t]{4}{*}{ Sex of baby } & Wilks' Lambda & 0.9545 & 0.8800 & $0.5653 e$ \\
\hline & Pillai’s Trace & 0.0455 & 0.8800 & $0.5653 a$ \\
\hline & Hotelling's-Lawey & 0.0477 & 0.8800 & $0.5653 a$ \\
\hline & Trace Roy's Greatest Root & 0.0477 & 0.8800 & $0.5653 u$ \\
\hline \multicolumn{5}{|c|}{ Test of Equality(Level) } \\
\hline & Wilks' Lambda & 0.9999 & 0.2300 & $0.6323 e$ \\
\hline & Pillai's Trace & 0.0001 & 0.2300 & $0.6323 a$ \\
\hline & Hotelling's-Lawe & 0.0001 & 0.2300 & $0.6323 a$ \\
\hline & Trace Roy's Greatest Root & 0.0001 & 0.2300 & $0.6323 u$ \\
\hline \multicolumn{5}{|c|}{ Test of Flatness } \\
\hline & Wilks' Lambda & 0.0075 & 2442.1900 & $0.0000 e$ \\
\hline & Pillai’s Trace & 0.9925 & 2442.1900 & $0.0000 a$ \\
\hline & Hotelling's-Lawey & 132.0101 & 2442.1900 & $0.0000 a$ \\
\hline & Trace Roy's Greatest Root & 132.0101 & 2442.1900 & $0.0000 u$ \\
\hline
\end{tabular}

e = exact, $a=$ approximate, $u=$ upper bound on $F$ 
3.2.8.2 Multivariate Tests of Parallelism, Equality and Flatness by Breast Feeding Type

From table 6, all the four multivariate tests for parallelism and equality indicated a $p$-value greater than 0.05 . We fail to reject the hypothesis of same profiles and conclude that the pattern of change in weights of babies did not differ by breast feeding for both parallelism and equality tests. The test of flatness was therefore carried out. The flatness test results revealed that all the four multivariate tests had p-values less than 0.05 . Hence the hypothesis of same profiles was rejected and conclusion stated that the pattern of change in mean weights of babies differed by breast feeding over the period of observation.

Table 6. Multivariate tests of parallelism, equality and flatness by Breast Feeding

\begin{tabular}{|c|c|c|c|c|}
\hline Source & Statistic & \multicolumn{2}{|l|}{ F Value } & Prob $>F$ \\
\hline \multicolumn{5}{|c|}{ Test of Parallelism } \\
\hline \multirow[t]{4}{*}{ Breast Feeding } & Wilks’'Lambda & 0.9332 & 0.6500 & 0.9004 \\
\hline & Pillai’s Trace & 0.0675 & 0.6500 & 0.9010 \\
\hline & Hotelling's-Lawey & 0.0707 & 0.6500 & 0.8999 \\
\hline & Trace Roy's Greatest Root & 0.0554 & 1.0300 & 0.4261 \\
\hline \multicolumn{5}{|c|}{ Test of Equality(Level) } \\
\hline & Wilks' Lambda & 0.9847 & 1.8000 & 0.1671 \\
\hline & Pillai's Trace & 0.0153 & 1.8000 & 0.1671 \\
\hline & Hotelling's-Lawey & 0.0153 & 1.8000 & 0.1671 \\
\hline & Trace Roy's Greatest Root & 0.0155 & 1.8000 & 0.1671 \\
\hline \multicolumn{5}{|c|}{ Test of Flatness } \\
\hline & Wilks' Lambda & 0.0093 & 1971.7600 & 0.0000 \\
\hline & Pillai’s Trace & 0.9907 & 1971.7600 & 0.0000 \\
\hline & Hotelling's-Lawey & 107.0641 & 1971.7600 & 0.0000 \\
\hline & Trace Roy’s Greatest Root & 107.0641 & 1971.7600 & 0.0000 \\
\hline
\end{tabular}

3.2.8.3 Multivariate Tests of Parallelism, Equality and Flatness by Maternal Age Group

All the four multivariate tests for parallelism and equality by age of the mother (Table 7) had a $p$-value $>0.05$. Hence, we fail to reject the hypothesis of same profiles and conclude that the pattern of change in weights of babies did not differ by maternal age group for both parallelism and equality tests. The results of the test of flatness proved that all the four multivariate tests showed p-values less than 0.05 . Thus, we reject the hypothesis of same profiles and conclude that the pattern of change in mean weights of babies did not remain the same by maternal age group over time.

Table 7. Multivariate tests of parallelism,equality and flatness by Maternal Age Group

\begin{tabular}{|c|c|c|c|c|}
\hline Source & Statistic & & F Value & Prob $>F$ \\
\hline \multicolumn{5}{|c|}{ Test of Parallelism } \\
\hline \multirow{4}{*}{$\begin{array}{l}\text { Maternal age } \\
\text { group }\end{array}$} & Wilks' Lambda & 0.9290 & 0.6900 & 0.8600 \\
\hline & Pillai's Trace & 0.0720 & 0.6900 & 0.8580 \\
\hline & Hotelling's-Lawey & 0.0760 & 0.6900 & 0.8610 \\
\hline & Trace Roy's Greatest Root & 0.0510 & 0.9500 & 0.4980 \\
\hline \multicolumn{5}{|c|}{ Test of Equality(Level) } \\
\hline
\end{tabular}




\begin{tabular}{|l|l|l|l|l|}
\hline & Wilks' Lambda & 0.9960 & 0.5000 & 0.6070 \\
& Pillai's Trace & 0.0040 & 0.5000 & 0.6070 \\
& Hotelling's-Lawey & 0.0040 & 0.5000 & 0.6070 \\
& Trace Roy's Greatest Root & 0.0040 & 0.5000 & 0.6070 \\
\hline \multicolumn{4}{|c|}{ Test of Flatness } \\
\hline & Wilks' Lambda & 0.0090 & 1945.9900 & 0.0000 \\
& Pillai's Trace & 0.9910 & 1945.9900 & 0.0000 \\
& Hotelling's-Lawey & 105.6640 & 1945.9900 & 0.0000 \\
& Trace Roy's Greatest Root & 105.6640 & 1945.9900 & 0.0000 \\
\hline
\end{tabular}

\subsubsection{Multivariate Tests of Parallelism, Equality and Flatness by Parity Group}

From table 8 , the four multivariate tests for parallelism and equality in each case showed $p$-values higher than 0.05 .Therefore, we fail to reject the hypothesis of same profiles and conclude that the pattern of change in weights of babies were the same by parity group in the two cases. Performing test of flatness revealed that all the four multivariate tests had $p$-values less than 0.05 . Therefore, we reject the hypothesis of same profiles and conclude that the pattern of change in mean weights of babies were not constant by parity group overtime.

Table 8. Multivariate tests of parallelism, equality and flatness by Parity Group

\begin{tabular}{|c|c|c|c|c|}
\hline \multicolumn{2}{|c|}{ Source } & Statistic & F Value & Prob $>F$ \\
\hline \multicolumn{5}{|c|}{ Test of Parallelism } \\
\hline \multirow[t]{4}{*}{ Parity group } & Wilks' Lambda & 0.8660 & 0.9000 & 0.6350 \\
\hline & Pillai's Trace & 0.1390 & 0.9000 & 0.6360 \\
\hline & Hotelling's-Lawey & 0.1490 & 0.9000 & 0.6340 \\
\hline & Trace Roy's Greatest Root & 0.0870 & 1.6000 & 0.0920 \\
\hline \multicolumn{5}{|c|}{ Test of Equality(Level) } \\
\hline & Wilks' Lambda & 0.9890 & 0.8500 & 0.4680 \\
\hline & Pillai's Trace & 0.0110 & 0.8500 & 0.4680 \\
\hline & Hotelling's-Lawey & 0.0110 & 0.8500 & 0.4680 \\
\hline & Trace Roy's Greatest Root & 0.0110 & 0.8500 & 0.4680 \\
\hline \multicolumn{5}{|c|}{ Test of Flatness } \\
\hline & Wilks' Lambda & 0.0130 & 1127.3500 & 0.0000 \\
\hline & Pillai's Trace & 0.9870 & 1127.3500 & 0.0000 \\
\hline & Hotelling's-Lawey & 75.2870 & 1127.3500 & 0.0000 \\
\hline & Trace Roy's Greatest Root & 75.2870 & 1127.3500 & 0.0000 \\
\hline
\end{tabular}

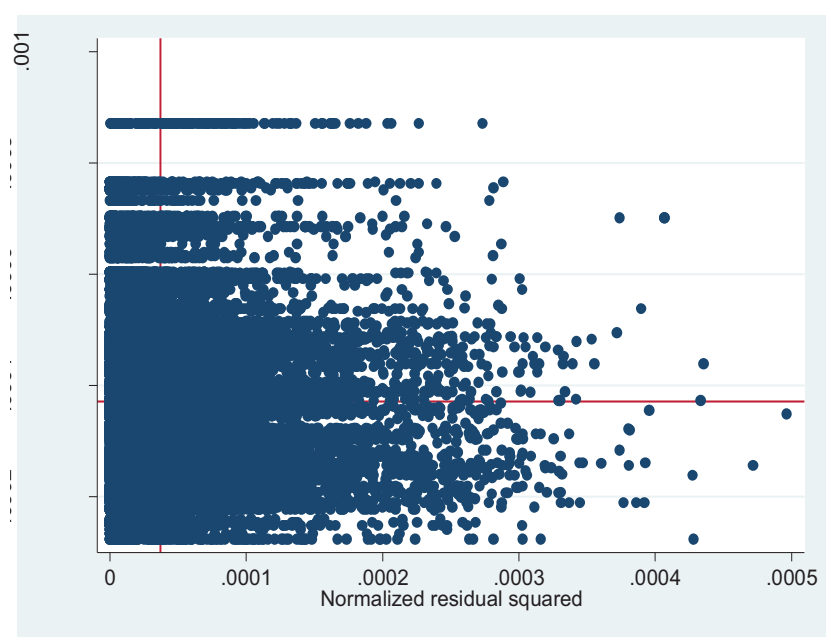

(a) 


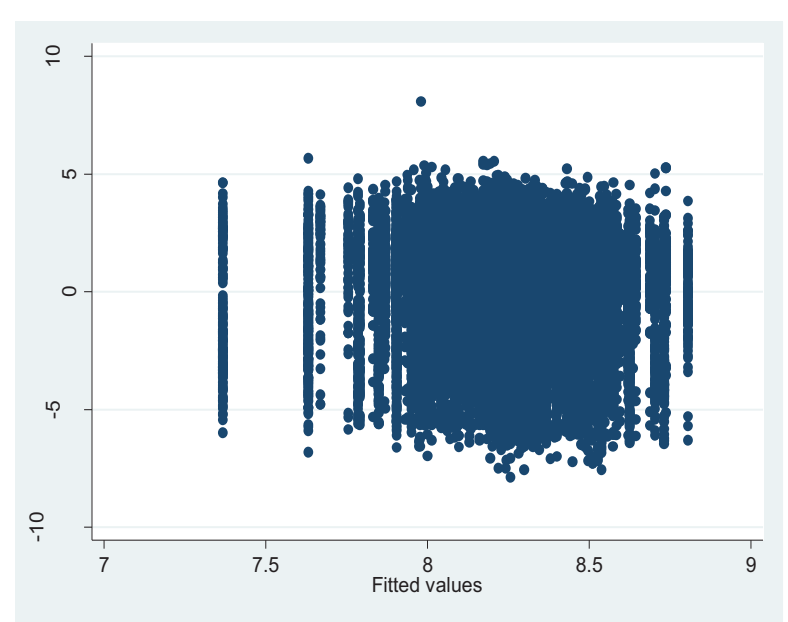

(b)

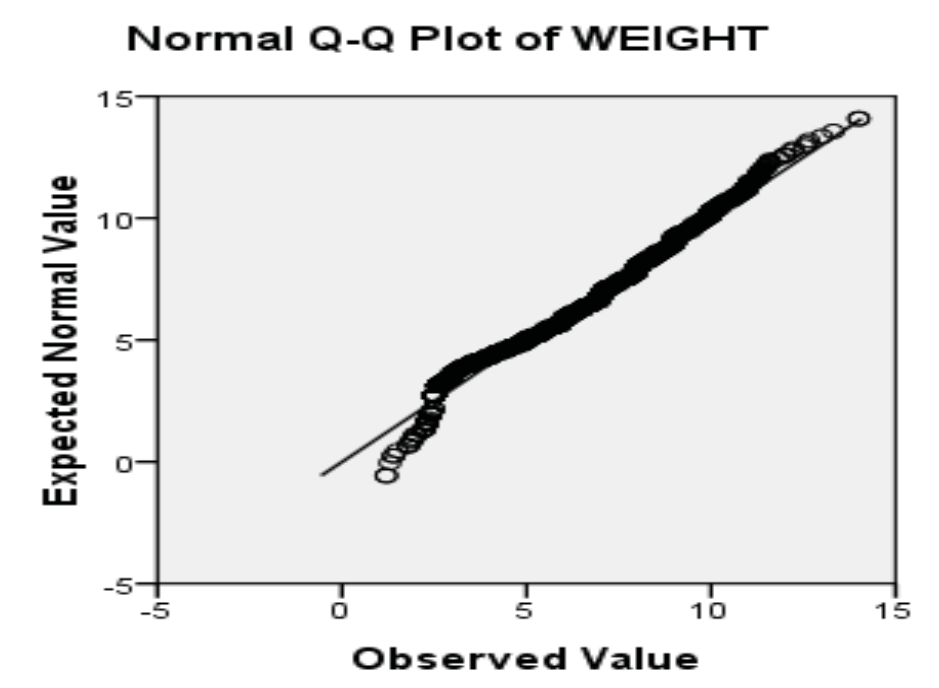

(c)

Figure 9. Residual Plots of weights of babies (a, b, c)

\section{Discussion}

The medical records of three hundred (300) weights of babies from the seven health facilities in the Bolgatanga municipality were monitored from January 2013 to December 2013 retrospectively. Sixty five (65) of these records were dropped out due to the inability of the nursing mothers to attend at least six post natal cares within the year. The remaining eligible two hundred and thirty five (235) records of weights of babies were included in this study for the analysis. Out of the two hundred and thirty five participants, 130 were males whilst 105 represented females but females averagely weigh slightly higher than males for mean birth weights: males and females were $2.71 \mathrm{~kg}$ and $2.74 \mathrm{~kg}$ respectively. The birth weights could be said to be good since in both sexes it was higher than the recommended standard for normal birth weights of $2.50 \mathrm{~kg}$ by the World Health Organization. 


\section{Mll Macrothink}

Journal of Biology and Life Science

ISSN 2157-6076

2015, Vol. 6, No. 2

The profile plot of the mean weights of babies per the breastfeeding type remained the same for month zero to month one which is obvious since a one month old child depends exclusively on breast milk. Among the three classes of breastfeeding types, infants who were not exclusively breastfed $(20.850 \%)$ for the first six months of birth realised the best mean baby weights compared to babies who solely depended on breast milk and infants who took breast milk and water only (mixed). This means that there should be a second consideration of the exclusive breastfeeding recommendation depending on the nutritional status and socio-cultural practices of the nursing mother. This result indicated that breastfeeding type is important in infant growth as reported by Sokol et al. (2007) that poor feeding practices including sub-optimal breastfeeding is still widespread and also results in malnutrition which mostly cause more than half of all child mortalities.

The pattern indicated by the profile of mean change in weight by mothers' educational level explained that mothers who attained tertiary level of education delivered babies with better mean birth weights and subsequent weights than mothers who had no education and those who completed primary school. This is due to high educated mothers' better understanding of and adherence to maternal and child health care educations offered by midwives and other health service providers. This supported the findings of Joyce (1994) who concluded that maternal highest level of education belongs in both the demand function and the birth weight production function, thus a greater influence in giving birth to overweight or normal babies compared to maternal parents whose educational level is very low or nil. Rosenzweig and Schultz (1983), however, were of the view that parental education affected the choice of health inputs but has no direct effect on birth weight. The profile plot for religion also proved an interesting pattern of an approximately constant increasing growth of average change in weights of babies for Christian and Muslim mothers whilst those of babies born by mothers affiliated to traditional religion showed fluctuating pattern. It is possible that some religious oriented socio-cultural beliefs and practices might have direct or indirect effects on the baby weights. In the North Indian, Dhall and Bagga (1995) revealed a significant effect of religion on birth weight among babies as well as the effect of maternal age on birth weight.

Type of contraceptive used prior to pregnancy showed injectable to have better growth pattern than that of the other family planning types as demonstrated in profile plots with baby weights.. Another fascinating profile plot is the one of baby weight by mothers' age group. There were very close similarities exhibited by mean change in weights of the babies by all the maternal age groups over the twelve months follow-up period with younger mothers (17 - 24 years) leading slightly. This thereby implies that late teens and adolescents have the potential of delivering babies with relatively high weights. The pattern of profile of baby weight by mother's occupation brought to light equivalent average change of the baby weights. Occupation in the analysis was not significant confirming Conley \& Bennett (2000) findings that no occupational income or education has effects on the probability of low birth weight among infants. The profile of baby weights by mother's parity group showed that mothers who gave birth up to two-three times had the best mean change in weights of babies compared to those who gave birth once as well as those who had four-five number of births which was the least. This indicated that parity level had positive effect in baby weights but after three times of 
delivery, it had a negative impact on birth weight of babies.

In identifying the pattern of change in weight of baby by gender, it was realised that the mean change in weights of babies for males and females were similar and increased over time. The test of parallelism, equality and flatness revealed the same and identical pattern for both sexes with the mean change in weight of baby varying over time. Therefore, the sex of baby had no significant influence on the weight of the baby but time had implying that time and gender did not interact. The time-effect on the weight of the baby was expected since growth of every organism (measurable by size, height, weight, cell mass and divisions etc.) is time dependent.

The test of parallelism and equality (test of levels) strongly proved that maternal factors such as educational status, age, last type of family planning employed as well as biological factors of both nursing mother and the baby including breastfeeding and sex of baby were statistically not significant but flatness was at 5\% significance level. Meanwhile, maternal factors such as: religious affiliations, occupation, parity, injection as at last type of family planning practiced by nursing mother were significant. Thus, the mean weight of a baby in the municipality can significantly be predicted by maternal factors such as occupation, parity group, injectable family planning method, breastfeeding type, level of education and religion, Parallelism test gave the confirmation that there existed differences in the pattern for the various educational levels indicated in the profile plot. The distinct rate and pattern of increment portrayed for mean weights of babies whose mothers attained tertiary level of education is in favor of Sachdeva and Valenzuela (2013) who found out that a rising level of education is a protective factor against low birth weight as well as Silvestrin et al., (2013) whose findings concluded that the lower the educational level of the mother, the greater the vulnerability of delivering a baby with a low birth weight. Therefore, nursing mothers with tertiary qualification have the weights of their babies higher compared to the nursing mothers without higher educational level or none. Also, there were no differences in the weights of babies by mother's age groupings contrary to Gibbs et al., (2012) who showed that young age is associated with a short cervix and a small uterine volume which is associated with preterm birth and consequently low birth weight.

\section{Conclusion}

The analysis revealed that even-though there existed some mean change in weights of males and females from the month of birth to a one year period, change in their mean weights were the same for gender. However, both males and females had mean birth weights of $2.71 \mathrm{~kg}$ and $2.74 \mathrm{~kg}$ respectively and is higher than the standard normal birth weights of $2.50 \mathrm{~kg}$ recommendation by the World Health Organization.

The profile of the determinants of the growth of children within the first year period showed that maternal factors such as educational status, age as well as biological factors such as breastfeeding and sex of baby were statistically not significant except flatness at 5\% significance level. We therefore failed to reject the null hypothesis of same profiles and conclude that the pattern of change in weights of babies did not differ by these groups. Among these non-significant determinants, however, mothers with higher education and nonexclusive breastfeeding had better influence on the weights of their babies. Nonetheless, maternal 


\section{Mll Macrothink}

Journal of Biology and Life Science ISSN 2157-6076 2015, Vol. 6, No. 2

factors such as: religious affiliations, occupation, parity, injection as at last type of family planning practiced by nursing mothers were significant. Hence from the profile analysis, the mean weight of a baby in the municipality could be modeled for predictions using the maternal factors such as occupation, parity group, injectable family planning method, breastfeeding type, level of education and religion. The profiles of the effects of both the maternal socio-demographics and biological factors on the weights of babies considered in this study established that the non-linear growth in weights of infants can be improved significantly by the nursing mothers, health service providers and the government if efforts are made to improve and/or modify the significant health indicators.

\section{Ethical consideration}

Ethical approval was obtained from the municipal health directorate. An informed written and verbal consent was sought from the management units of all the health facilities and the nursing mothers involved in the study. The data collection procedures did not involve direct contact with subjects and the analyses were totally free of any personal identifiable information to ensure confidentiality and privacy.

\section{Acknowledgement}

This research was financed by the researchers. We, however, want to sincerely thank the following for their various supports to make this study successful. We thank the officials of the Bolgatanga regional hospital, Zuarungu Health Centre, Amiah Hospital, Asankunde Health Centre, Coronation Health Centre (Plaza), Aningazanga Health Centre and Afrikids Medical Centre and all nursing mothers whose children were involved in this study by supporting the study with the requisite data. Another big thank to our entire families, friends and co-workers for all the support and encouragement we had received from them. God bless you all

\section{References}

Caulfield, L. E., De Onis, M., Blossner, M., \& Black, R. E. (2004). Under nutrition as an underlying Cause of child deaths associated with diarrhoea, pneumonia, malaria and measles. American Journal of Clinical Nutrition, 80, 193-198

Conley, D., \& Bennett (2000). Birth weight and income: Interactions across Generations. Journal of Health and Social Behaviour, 42(12), 450-465

Dreyfuss, M. L., Msamanga, G. I., Spiegelmam, D., Hunter, D. J., Ernest, Urassa, E. J. N., Hertzmark, E., \& Fawzi, W. W. (2001). Determinants of Low Birth Weight among HIV-infected pregnant women in Tanzania, American Journal of Clinical Nutrition, 74(6): 814-826.

Dhall, K., \& Bagga. R. (1995). Maternal determinants of birth weight of North Indian babies. The Journal of Pediatrics volume, 62(3), 333-344.

Engle, R. F., Hendry, D. F., \& Trumble, D., (1985). Small sample properties of ARCH estimators and tests. Canadian Journal of Economics 18, 66(93)

Fawzi, W. W. (2001). Determinants of Low Birth Weight among HIV-infected pregnant women 
in Tanzania, American Journal of Clinical Nutrition, 74(6). 814-826.

Gortmaker, S. L., \& Wise, P. (1997). The First In justice: Socio-economic Disparities, HealthServices Technology and Infant Mortality. Annual Review of Sociology, 23, 147-70. http://dx.doi.org/10.1146/annurev.soc.23.1.147

Gibbs, C. M., Wendt, A. A., Peters, S. S., \&Hogue, C. J. (2012). The impact of early age at first child birth on maternal and infant health. Paediatric and Perinatal Epidemiology, 26(1), 259-284. http://dx.doi.org/10.1111/j.1365-3016.2012.01290.x

Joyce, T. (1994). Self-selection, prenatal care and birth weight among blacks whites and Hispanics in New York City. Journal of Human Resources, 29, 762-794. http://dx.doi.org/10.2307/146252

Luguterah, A., \& Nokoe, K. S (2013). Comparison of the significance of Some Fixed Factors on Multi Level Child Survival. European Scientific Journal vol.9, No.18

McCormick, M. C. (1985). The contribution of low birth weight to infant mortality and childhood morbidity, New England Journal of Medicine, 312, 82-90. http://dx.doi.org/10.1056/NEJM198501103120204

Murthy, H. V. V. (1991). Birth weight and the associated factors-a review. Ind J Soc Work. 11, 151-156.

Sachdeva, P. S., \& Valenzuela, M. (2013). Brain and cognitive reserve. Am J Geriat Psychiat, 17, 175-178. http://dx.doi.org/10.1097/JGP.0b013e318196a661

Shapiro, S. S., \& Wilk, M. B. (1980). An analysis of variance test for normality (complete samples), Biometrika, 52, 591-611. http://dx.doi.org/10.1093/biomet/52.3-4.591

Silvestrina, S. S., \& Sachdeva, R. R. (2013). Comparative analysis of birth weight in a hospital over a decade: low birth weight still a major problem. Journal of Nepal Paediatric Society, $33(1), 15-20$

Sokol, E., Aguayo,V., \& Clark, D., (2007). Protecting breastfeeding in West and Central Africa: 25 years implementing the international code of marketing breast milk substitutes. Unicef Publication

Rosenzweig, M. R., \& Schultz, T. P. (1983). Estimating a household production function heterogeneity, the Demand for Health inputs, and their effects on birth weight. Journal of Political Economy, 91(5), 723-746. http://dx.doi.org/10.1086/261179

UNICEF and WHO (2004). Low Birth weight: Country, Regional and Global Estimates. New York: UNICEF.

Yinger, N. V. and Ransom, E. I. (2003). Why Invest in Newborn Health. Population Reference Bereau. 


\section{Macrothink}

Journal of Biology and Life Science

ISSN 2157-6076

2015, Vol. 6, No. 2

Abbreviation

ANOVA Analysis of variance

AIC Akaike's information criterion

BIC Bayesian Information Criterion

IUGR Intrauterine growth retardation

JHS Junior High School

LBW Low Birth Weight

MANOVA Multivariate analysis of variance

MDG4 Millennium Development goals four

SHS Senior High School

UNICEF The United Nations Children's Fund

WHO: World Health Organisation

\section{Copyright Disclaimer}

Copyright for this article is retained by the author(s), with first publication rights granted to the journal.

This is an open-access article distributed under the terms and conditions of the Creative Commons Attribution license (http://creativecommons.org/licenses/by/3.0/). 